\title{
Coparentalidade e Conflito Pais-Filhos em Adolescentes Envolvidos em Práticas Restaurativas
}

\author{
Cristiane Koch $^{1}$ \\ Jeferson Rodrigo Schaefer ${ }^{2}$ \\ Mariana Cunba Schneider ${ }^{2}$ \\ Clarisse Pereira Mosmann ${ }^{2}$ \\ ${ }^{1}$ Universidade de Caxias do Sul \\ ${ }^{2}$ Universidade do Vale do Rio dos Sinos
}

\begin{abstract}
Resumo
Coparentalidade é definida como a relação estabelecida entre os cuidadores e a forma como compartilham os cuidados com seus filhos. Suas reverberações nos filhos adolescentes podem ser associadas a problemas de comportamento, condutas antissociais. Investigou-se o efeito preditor das dimensões da coparentalidade e do conflito pais-filhos em condutas antissociais de adolescentes em conflito com a lei no contexto das práticas restaurativas. Sessenta e dois adolescentes vinculados a projeto do Ministério Público no Rio Grande do Sul que responderam quatro escalas. Os resultados, a partir de regressão linear, sustentam que as variáveis - triangulação coparental familiar, intensidade e motivo de conflito com o pai são preditoras de comportamentos antissociais leves. Nos severos, o conflito coparental familiar teve o maior poder preditivo. Esses dados evidenciam a necessidade de valoração da relação familiar - coparental, instrumentalizando medidas protetivas que garantam a saúde mental do adolescente, buscando sua proteção à de condutas de risco.

Palavras-chave: adolescente em conflito com a lei, coparentalidade, conflito familiar
\end{abstract}

\section{Coparenting and Parent-Children Conflict in Adolescents Involved in Restorative Practices}

\begin{abstract}
Coparenting is defined as the relationship established between caregivers and the way they share the care for their children. The reverberations in adolescents may be associated with behavioral problems - antisocial behavior. The present study investigated the predictive effect of the dimensions of coparenting and parent-child conflict on antisocial behavior of adolescents in conflict with the law in the context of restorative practices. The survey sample included 62 adolescents linked to a project conducted by the Public Prosecution Service (MP) in the state of Rio Grande do Sul, who answered four scales. The results, based on linear regression, support that the variables - family coparental triangulation, intensity and reason for conflict with the father - are predictive of mild antisocial behavior. In severe cases, family coparental conflict had the greatest predictive power. These data highlight the need to evaluate the family-coparental relationship, in order to support protective measures that guarantee adolescent mental health, seeking their protection against risky behaviors.
\end{abstract}

Keywords: adolescent in conflict with the law; coparenting; family conflict

Coparentalidad y Conflicto Padres-Hijos en Adolescentes Involucrados en Prácticas Restaurantes

\begin{abstract}
Resumen
Crianza Conjunta---Coparenting---Coparentalidade--- es definida como la relación establecida entre los que cuidan de sus hijos y la forma que comparten los cuidados de los mismos. Las repercusiones en los hijos adolescentes pueden estar asociadas a problemas de comportamiento, conductas antisociales. El estudio investigó el efecto predictor de las dimensiones de la crianza conjunta y del conflicto padres-hijos en conductas antisociales de adolescentes, en conflicto con la ley en el contexto de prácticas de rehabilitación. El estudio contó con sesenta y dos adolescentes vinculados al proyecto del Ministerio Público en Río Grande del Sur que respondieron cuatro escalas. Los resultados, a partir de la regresión lineal, sostienen que las variables - triangulación crianza conjunta familiar, intensidad y motivo de conflicto con el padre son predictores de comportamientos antisociales leves. En los severos, el conflicto crianza conjunta familiar tuvo el mayor poder predictivo. Estos datos evidencian la necesidad de valorar la relación crianza conjunta familiar, instrumentando medidas protectoras que garanticen la salud mental del adolescente, buscando su protección alejándolo de conductas de riesgo.

Palabras clave: adolescentes en conflicto con la ley; crianza conjunta; conflicto familiar
\end{abstract}

\section{Introdução}

As configurações familiares, seu funcionamento e a forma como reverberam nas relações intrafamiliares e no desenvolvimento do adolescente são objeto de numerosas investigações nos últimos anos (Castro \& Theodoro, 2014; Formiga, 2014; Sbicigo \& Dell'Aglio, 2012). Os resultados apontam que o comportamento dos filhos sofre influências, não somente da relação que o adolescente entabula com os pais/ 
cuidadores, mas também de aspectos da conjugalidade, coparentalidade e parentalidade (Mosmann, Costa, Einsfeld, Silva, \& Koch, 2017; Neumann \& Zordan, 2013). Há evidências de que as interações conflituosas estabelecidas entre os cuidadores podem impactar toda a família, tendo associações com problemas emocionais e de comportamento dos adolescentes. Esses podem se caracterizar como sintomas externalizantes por meio de condutas antissociais - violação de leis e normas sociais, dificuldades de administrar frustrações, evasão e fracasso escolar, entre outras atitudes (Silveira, Maruschi, \& Bazon, 2012). Ou ainda, apresentar padrões de conduta privados desajustados, como depressão, tristeza, isolamento, conceituados como comportamentos internalizantes (Padovani, Schelini, \& Williams, 2009).

As formas como os subsistemas familiares se inter-relacionam e se expressam na unidade familiar parece desencadear implicações para o desenvolvimento e funcionamento psicológico da família e dos filhos. Há vários estudos que buscam descrever como as variáveis da relação conjugal e pais-filhos podem reverberar no comportamento da prole e, em especial, as pesquisas vêm se intensificando, no subsistema coparental e suas múltiplas dimensões, pelo fato de desvelar com maior amplitude os impactos da relação dos pais/cuidadores no desenvolvimento dos filhos (Lamela \& Figueiredo, 2016; Mosmann et al., 2017; Riina \& McHale, 2014; Teubert \& Pinquart, 2010).

Entende-se como coparentalidade a forma como os cuidadores se relacionam, dividem a condução, responsabilidades, apoio e coordenação (ou falta de) sobre os filhos (Feinberg, 2003). Nessa linha, é possível afirmar que a coparentalidade visa ao envolvimento conjunto, recíproco dos cuidadores em relação à tomada de decisões quanto à condução e vida da prole (Feinberg, 2003; Lamela, Costa, \& Figueiredo, 2010). É o responsabilizar-se conjuntamente pelo bem-estar dos filhos, sem a equivalência de papéis ou autoridade parental, uma vez que, a atuação dos pais ou participantes da unidade familiar vai além da conjugalidade/parentalidade e persiste, mesmo com a separação, divórcio e o convívio em novos arranjos familiares. A relação coparental materializa-se quando, ao menos dois indivíduos, na comunhão de esforços, num acordo mútuo, assumem a responsabilidade conjunta por um adolescente.

A coparentalidade como construto multidimensional apresenta, sob o viés de Margolin, Gordis e John (2001), três dimensões: conflito, cooperação e triangulação. O quesito conflito vincula-se a (dis)concordância dos pais sobre aspectos parentais no trato com os filhos; são as discussões sobre as práticas educativas, do (des) acordo e (in)flexibilidade quanto a princípios e posturas na formação da criança/adolescente e de normas gerais sobre a rotina da família. O componente cooperação se remete ao suporte social e emocional que os pais despendem mutuamente para a condução da unidade familiar e criação dos filhos. A dimensão da triangulação está associada às relações intergeracionais entre os genitores e filhos, em especial, busca apreender o impacto desencadeado pela distorção entre os limites pais-filho, ao formar uma parceria com o intento de minar ou excluir a presença do outro genitor.

$\mathrm{Na}$ adolescência, os filhos estão passando por um período de transição (de um modelo ou controle externo para o autocontrole, além dos aspectos biológicos, psicológicos e sociais) caracterizado, na maioria das vezes, como um momento de crise. A delimitação dos papéis e figuras parentais é fundamental para administrar a crise e garantir um funcionamento familiar saudável e propiciar bem-estar ao adolescente, pois é no ambiente familiar que são estabelecidas as referências para o adolescente construir sua identidade (Nardi \& Dell'Aglio, 2012; Zappe \& Dias, 2012).

Em relação aos adolescentes em conflito com a lei, as pesquisas apontam que a variável comportamento antissocial está negativamente associada ao comportamento e apoio emocional dos pais e há indícios de que práticas parentais punitivas e abusivas tendem a se associar positivamente a comportamentos antissociais (Rossato \& Souza, 2014). Adolescentes expostos a eventos ou situações adversas em suas histórias familiares, tanto no sentido de mudança em sua configuração inicial - morte, divórcio -, quanto em decorrência de situações ou problemas de natureza crônica - alcoolismo, doença mental dos genitores -, são expostos a adversidades que, em longo prazo, comprometem o seu saudável desenvolvimento. Circunstâncias que podem ser agravadas e desencadearem condutas antissociais quando a esses fatores, restar agregada a violência intrafamiliar, não só em nível de prática parental - como corretivos e castigos envolvendo violência (Nunes, Andrade, \& Moraes, 2013; Predebon \& Giongo, 2015), como, também, no relacionamento entre os pais - cuidadores, no qual o adolescente é exposto a brigas e discussões (Nardi \& Dell'Aglio, 2012; Silveira et al., 2012).

Em revisão na literatura, encontraram-se estudos internacionais que sustentam que o comportamento antissocial dos filhos está associado tanto à relação pais-filhos quanto à coparentalidade, e suas dimensões como suporte - conflito e cooperação. A pesquisa de Feinberg, Kan e Hetherington (2007) investigou os efeitos do conflito coparental e os reflexos nas condutas 
antissociais. Os resultados indicaram que o conflito coparental associado a moderadores, como gênero, idade, estrutura familiar, entre outros, são fatores de risco que inter-relacionados desencadeiam as práticas delitivas. E mais, cria-se uma dinâmica de retroalimentação entre essas condutas de risco, associadas ao ambiente familiar conflituoso gerando um convívio ainda mais estressante para os cuidadores, implicando em comportamentos parentais negativos, como punições excessivas e inadequadas, desencadeando, por sua vez, mais conflitos coparentais.

$\mathrm{Na}$ mesma linha, o estudo de Baril, Couter, e McHale (2007) analisou uma amostra de 177 famílias em que os pais e o primogênito adolescente participaram, ao longo de um ano, de entrevistas. A pesquisa teve como propósito descrever as percepções do casal sobre coparentalidade (cooperação, conflito e triangulação) bem como as associações estabelecidas na estrutura familiar, além de verificar como o amor conjugal e a coparentalidade reverberam no bem-estar do adolescente. Nos dados aferidos, quanto à coparentalidade na dimensão conflito, observou-se um aumento relativo ao comportamento de risco, tendo como moderador o amor conjugal. Evidencia-se que as intervenções relacionadas às relações conjugais e à coparentalidade podem modificar o comportamento de risco dos adolescentes. Contudo, não restou evidenciada a relação entre as dimensões cooperação ou triangulação. Há indícios nos resultados de associação entre a coparentalidade com o comportamento dos adolescentes, mais especificamente, no conflito coparental que se relaciona a sintomas depressivos para os adolescentes indistintamente e comportamentos de risco para meninos.

Também merece destaque a metanálise desenvolvida por Teubert e Pinquart (2010) no qual buscaram, por meio da integração de 59 estudos, verificar a relação estabelecida entre a coparentalidade (cooperação, acordo, conflito e triangulação) e a adaptação, não só da criança, mas, também, do adolescente. Os resultados evidenciaram que, novamente, o conflito coparental está associado a sintomas externalizantes, já a triangulação está vinculada a efeitos internalizantes. A obtenção desses resultados foi moderada, em certa medida, pelas variáveis: idade, gênero, renda e configuração familiar.

Em um estudo longitudinal Feinberg et al., (2007), envolvendo 516 famílias, em que avaliaram duas dimensões da coparentalidade, a cooperação - compartilhamento de decisões e participação nas atividades que envolvem o adolescente e a triangulação - nas associações bidirecionais, em especial, no comportamento de risco (externalizantes) e de sintomas depressivos (internalizantes) examinando-os sob a perspectiva de gênero, observou-se que, em relação aos meninos, a relação entre baixa cooperação e acordo foi preditora de comportamento de risco. Já, quanto aos sintomas depressivos, verificou-se que esses sintomas internalizantes apresentaram resultados semelhantes para meninos e meninas e que ambos foram preditores para um menor envolvimento coparental. Esses resultados também sugerem que os sintomas internalizantes são menos perceptíveis do que as condutas de risco, revelando que os pais estariam mais comprometidos em concentrar sua atenção em problemas de ajustamento mais evidentes ou facilmente identificáveis.

Riina e McHale (2014) realizaram estudo sobre as influências bidirecionais da coparentalidade no ajustamento dos adolescentes. A pesquisa avaliou duas dimensões da coparentalidade - o compartilhamento entre pais-cuidadores na tomada de decisão, o envolvimento nas atividades com os filhos adolescentes e as associações bidirecionais de comportamento de risco em meninos e possíveis sintomas depressivos nas meninas. Participaram 201 pessoas entre pais, mães e adolescentes. Os resultados revelam que, em média, os pais de meninos compartilham mais a tomada de decisão, mas inversamente proporcional é o envolvimento paterno nas atividades com os adolescentes. Observou-se que no cruzamento da variável comportamento de risco e o compartilhamento de decisões restaram diretamente relacionados logo, quanto mais compartilhamento, menor o comportamento de risco entre os adolescentes. Já quanto ao envolvimento dos pais em atividades, tanto para meninos como meninas, a participação nas atividades dos cuidadores reduz os comportamentos de risco. No que tange a sintomas depressivos, para os adolescentes, independentemente do gênero, o não envolvimento em atividades é um forte preditor.

$\mathrm{Na}$ literatura nacional, há parcos estudos que tratam da coparentalidade e seus reflexos na conduta de crianças e adolescentes, contudo, nessas pesquisas, a coparentalidade é avaliada juntamente com outros subsistemas familiares, isto é, com parentalidade e conjugalidade (Mosmann et al., 2017). Nesse estudo, envolvendo 200 indivíduos e seus filhos, apurou-se, de forma geral, que há indicativos de que a forma com que os filhos se comportam está vinculada à relação pai-filhos e às dimensões da coparentalidade, em especial, quando os pais falham no apoio mútuo, ou quando apresentam práticas educativas contraditórias ou que desqualificam o outro cuidador. Os comportamentos externalizantes foram preditos pelas 
dimensões de competição coparental, exposição ao conflito coparental, entre outras. Nessa senda, segue o estudo de Mosmann, Costa, Silva e Luz (2018) que verificam os subsistemas familiares e, no que tange à coparentalidade, identificaram indícios de que o comportamento da prole é afetado quando não há suporte entre os cuidadores/pais, pela adoção de práticas educativas contraditórias, além das variáveis das dimensões coparentalidade - competição e conflito coparental apresentarem maior poder discriminante. Compete também destacar os estudos que relacionam a coparentalidade como mediadora entre a relação conjugal e o ajustamento dos filhos nos quais demonstram que dimensões como baixa coesão conjugal e altos índices de conflito coparental se tornam preditores de problemas de comportamento transgressor nos filhos (Nardi \& Dell'Aglio, 2012; Predebon \& Giongo, 2015).

Apesar dos avanços dos estudos sobre esse subsistema, bem como a forma que impacta no desenvolvimento de crianças/adolescentes, a coparentalidade e suas dimensões, em especial, em adolescentes em conflito com a lei, não foram amplamente analisadas. É nesse contexto que esse estudo investigou o efeito preditor das dimensões da coparentalidade dos cuidadores e do conflito entre pais-filhos em condutas antissociais de adolescentes em conflito com a lei. Ressalta-se a importância de analisar a relação entre essas variáveis sob um novo prisma, por meio da percepção dos adolescentes, e não só pelo crivo dos pais ou cuidadores (Sbicigo \& Dell'Aglio, 2012), em um lócus diferenciado "das práticas restaurativas", por envolver adolescentes em conflito com a lei nos círculos restaurativos.

Essa pesquisa integrou um projeto maior, o qual ocorreu em um setting privilegiado, ao longo dos círculos restaurativos, decorrentes de uma iniciativa pioneira do Ministério Público gaúcho, que instrumentalizara uma política pública de uma cidade serrana do Rio Grande do Sul. Amparada em um novo paradigma de resposta jurisdicional, a justiça restaurativa tem como objetivo a transformação dos conflitos, resgatando valores como justiça social, empoderamento, pertencimento e corresponsabilização, pois a comunidade é partícipe no processo, refletindo com o ofensor e vítima os fatos desencadeadores da violência e do ato infracional (Salmaso, 2016). Visa promover medidas que minimizem as causas propulsoras das transgressões, respeitando as necessidades tanto do ofensor quanto vítima e entorno, mas sem descurar das obrigações e reparações materiais e morais decorrentes dos atos infracionais cometidos em âmbito escolar.

\section{Método}

\section{Delineamento}

Trata-se de um estudo explicativo de caráter quantitativo, tendo como referencial pressupostos sistêmicos (Vasconcellos, 2002).

Amostra

Os instrumentos foram aplicados em um espaço diferenciado, propiciado pelo "Projeto de atenção especial à violência escolar", que surgiu por meio da adoção de política municipal e iniciativa do MP/ RS como forma de, a partir de práticas restaurativas exitosas no país, implementar uma alternativa à violência escolar, através de soluções autocompositiva, dialógica e não persecutória, envolvendo toda a rede de apoio (escola e comunidade), o judiciário, além da família e adolescentes.

Os casos de violência de menor potencial ofensivo, remetidos ao projeto, representam conflitos ocorridos no ambiente escolar ou seu entorno, nos quais as respostas apresentadas pela Escola e DPCA não surtiam mais efeitos, dividindo-se assim com toda a comunidade a responsabilidade de se transformar o conflito, buscando reforçar o sentimento de pertencimento e reconstruindo as relações sociais abaladas pelo fato.

Nesse contexto restaurativo, os casos atendidos no MP eram acompanhados por facilitadores que conduziam os pré-circulos, círculos e até pós-circulos. Nessas etapas restaurativas, o adolescente e sua unidade familiar eram orientados quanto à dinâmica e ouvidos. Caso tivessem interesse, as partes - ofensor e vítima, participavam dos círculos nos quais se definiam as melhores estratégias para a compreensão dos impactos dos danos causados e como reparar as mazelas desencadeadas pela violência.

Durante esse processo, todos adolescentes foram convidados a responder os instrumentos do presente estudo. Ao todo foram aplicados 124 instrumentos dos quais 62 restaram válidos para esta pesquisa que envolveu adolescentes que cometeram atos infracionais e que se encontravam em contexto de práticas restaurativas. Os jovens possuíam idades entre 12 e 18 anos, sendo a idade média $14,48(D P=1,46)$. Destes, $53,2 \%$ eram meninas e 46,8\%, meninos. A maior parte frequenta o ensino fundamental $(68,3 \%)$ e possuía renda familiar de até $\mathrm{R} \$ 1.448,00$ (45,3\%). Além disso, 69,4\% dos adolescentes residiam com o pai e a mãe; $1,6 \%$ com o pai e a madrasta; $8,1 \%$ com a mãe e o padrasto; $1,6 \%$ moravam apenas com o pai e 19,4\% viviam apenas com a mãe. 


\section{Instrumentos}

Questionário Sociodemográfico. Composto de 24 questões elaboradas pelo grupo de pesquisa. Referem-se aos dados sociodemográficos dos participantes (sexo, idade, escolaridade, renda familiar etc.).

Escala de Conflito Pais-filho (ECPF). A escala constitui-se de nove itens e está dividida em duas subescalas que se referem, respectivamente, à frequência com que os sujeitos experimentaram desentendimentos com seu pai e mãe no último ano e a frequência com que o adolescente resolve os conflitos de forma calma, com discussões ou agressões. A primeira subescala é medida em uma escala Likert de seis pontos e a segunda subescala possui três itens, pontuados em uma escala Likert de cinco pontos. Maiores escores na escala representam altos níveis de conflito Buehler e Gerard (2002), adaptado por Terres-Trindade e Mosmann (2015). O coeficiente alfa de Cronbach obtido para a ECPF total no presente estudo foi de 0,84 .

Escala de Coparentalidade para Pais e Adolescentes (The CoparentingInventory for Parentsand Adolescents, CI-PA) (Teubert \& Pinquart, 2010). Evidências de validade no Brasil por Mosmann et al., (2018). A escala permite que os adolescentes realizem uma avaliação em nível diádico e individual acerca do exercício da coparentalidade dos pais percebida pelos filhos. É composta por questões que investigam as três dimensões da coparentalidade, sendo os itens pontuados em uma escala Likert de quatro pontos. Neste estudo, os valores de alfa de Cronbach variaram entre 0,78 (avaliação do adolescente sobre a coparentalidade da mãe) e 0,80 (avaliação do adolescente sobre a coparentalidade do pai).

Escala de Comportamentos Antissociais (ECA) - (Construção e evidências de validade no Brasil por Grangeiro, 2014). Permite que os jovens façam uma autoavaliação em relação aos comportamentos antissociais leves e comportamentos antissociais severos, respondendo se já realizaram algum dos comportamentos de forma intencional. A escala avalia a frequência desses comportamentos utilizando uma escala Likert de cinco pontos. Os coeficientes alfa de Cronbach obtidos para esse estudo foram de 0,85 (comportamentos antissociais leves) e 0,67 (comportamentos antissociais severos).

\section{Procedimentos Éticos e de Coleta de Dados}

O projeto foi aprovado pelo Comitê de Ética em Pesquisa da Universidade Vale do Rio dos Sinos, sob parecer 14/152 (CAAE:36888214.0.0000.5344). Todos os adolescentes assinaram um Termo de Assentimento e seus responsáveis, um Termo de Consentimento
Livre e Esclarecido. O procedimento de coleta de dados se deu de forma individual, auxiliado pela pesquisadora.

A coleta de dados efetivou-se a partir da autorização do Poder Judiciário, Ministério Público e Central de Práticas Restaurativas e compreendera um período entre agosto/2015 a novembro/2017. Durante esse período, ocorrera alguns intervalos na apuração dos dados desencadeados pelas férias forenses e pela substituição dos Promotores responsáveis pela Promotoria de Justiça Especializada.

A partir dos casos selecionados pela Delegacia especializada e Ministério Público que comportassem as práticas, em data pré-agendada para a apresentação ao Promotor, os adolescentes eram convidados a participarem da pesquisa. A aplicação dos questionários, ora ocorrera antes da audiência com o Promotor, ora ao seu término, como uma das medidas socioeducativas determinadas, em ato contínuo aos pré-círculos, momento em que o adolescente e seu(s) pai(s) eram informados e convidados a participarem das práticas restaurativas. Tanto ao adolescente quanto ao seu responsável eram esclarecidas a razão do questionário, das implicações dos termos que assinaram e da duração média de uma hora para preenchimento do instrumento, tendo em vista que os questionários são autoaplicáveis. Todo o período de aplicação de instrumentos foi acompanhado pela pesquisadora que prestou esclarecimentos e orientações, quando se fizeram necessárias.

\section{Análise de Dados}

Inicialmente foram comprovados os critérios de supostos paramétricos. Para o procedimento de análise de dados, utilizou-se a análise de Correlação de Pearson $(r)$ para identificar possíveis associações entre os conflitos pais e filhos, as dimensões da coparentalidade e os comportamentos antissociais leves ou severos. Também se realizou análises de regressão linear para estabelecer modelos preditivos das variáveis independentes (motivo de conflito com a mãe, motivo de conflito com o pai, intensidade do conflito com a mãe, intensidade do conflito com o pai, cooperação coparental da mãe, conflito coparental da mãe, triangulação coparental da mãe, cooperação coparental do pai, conflito coparental do pai, triangulação coparental do pai, cooperação coparental da família, conflito coparental familiar, triangulação coparental familiar) sobre as variáveis dependentes (comportamentos antissociais leves ou severos).

As análises de regressão foram realizadas após a comprovação dos pressupostos conforme Hair, Black, 
Babin, Anderson e Tatham (2009). Verificou-se a ausência de multicolinearidade, pois os valores de tolerância para o modelo dos antissociais leves foram inferiores a 1, quanto aos resíduos, o coeficiente de Durbin-Watson foi de 2,4, situando-se entre 1,5 a 2,5. A homocedasticidade foi avaliada por meio de gráficos que comprovam sua presença. Em relação aos modelos dos antissociais severos, os valores de tolerância foram inferiores a 1 , o coeficiente de Durbin-Watson foi de 1,7, apresentou-se entre 1,5 a 2,5 e a homocedasticidade foi identificada por meio de gráficos.

\section{Resultados}

Em um primeiro momento, verificou-se as correlações significativas entre as dimensões de coparentalidade, conflitos pais-filhos e destas com os comportamentos antissociais leves e severos - Tabela 1 . Nessa linha, observou-se que, nas condutas antissociais leves, há associações significativas com as seguintes variáveis: motivo conflito com a mãe - MCM, motivo conflito com o pai - MCP, intensidade conflito com a mãe - ICM, conflito coparental do pai - CP, triangulação coparental do pai - TCP, conflito coparental familiar - CF e triangulação coparental familiar - TCF.

Já quanto aos comportamentos antissociais severos, apurou-se a associação dessas condutas com as seguintes dimensões da coparentalidade e conflito pais-filhos: motivo conflito com o pai - MCP, intensidade conflito com a mãe - ICM, cooperação coparental paterno - CCP, conflito coparental do pai - CP e triangulação coparental familiar - TCF. Também, merece análise a intensidade estabelecida entre as variáveis, apurou-se que entre as associações das variáveis nas condutas antissociais leves, na sua maioria, estabeleceram correlações fracas, salvo motivo de conflito com o pai - MCP, triangulação coparental familiar - TCF que apresentaram intensidade moderada. Já em relação aos conflitos antissociais severos, identificou-se que as correlações, também, apresentam, na sua maioria, intensidade fraca, com exceção triangulação coparental familiar - TCF e no conflito coparental familiar - CF que apresentam moderada intensidade.

Tabela 1.

Correlação de Todas as Variáveis Medidas

\begin{tabular}{|c|c|c|c|c|c|c|c|c|c|c|c|c|c|c|c|}
\hline & 1 & 2 & 3 & 4 & 5 & 6 & 7 & 8 & 9 & 10 & 11 & 12 & 13 & 14 & 15 \\
\hline 1 & 1,00 &, $671^{* *}$ & 0,156 &,- 073 & ,290* & 0,259 & 0,224 & 0,259 & $-0,05$ &, $502^{* *}$ & 0,087 &,- 145 &, $430^{* *}$ &, $353^{*}$ & 0,199 \\
\hline 2 & & 1,00 & 0,002 & 0,093 & 0,025 & 0,066 &,- 193 & $-0,07$ & ,283* &, $414^{* *}$ &,$- 316^{*}$ & 0,095 & 0,253 &, $438^{* *}$ &, $380^{* *}$ \\
\hline 3 & & & 1,00 &, $506^{* *}$ &,- 144 & 0,123 & ,292* &,- 146 & 0,061 & 0,079 & $-0,22$ & ,278* &, $502^{* *}$ &, $282^{*}$ &, $284^{*}$ \\
\hline 4 & & & & 1,00 &,- 218 &,- 064 & 0,045 &,- 257 & 0,214 & 0,094 &,$- 357^{* *}$ &, $396^{* *}$ & $369^{* *}$ & 0,155 & 0,065 \\
\hline 5 & & & & & 1,00 & 0,121 & 0,264 &, $879^{* *}$ & 0,203 & 0,197 &, $615^{* *}$ &,$- 721^{* *}$ &,- 085 &,- 122 &,- 117 \\
\hline 6 & & & & & & 1,00 & ,083 & ,291* &,$- 285^{*}$ & $-0,049$ & 0,235 &,- 214 & $-0,01$ & 0,04 &,- 014 \\
\hline 7 & & & & & & & 1,00 & 0,241 & 0,057 &, $380^{* *}$ & 0,167 &,- 206 & ,320* & 0,053 & $-0,01$ \\
\hline 8 & & & & & & & & 1,00 & 0,175 & 0,141 & ,698 &,$- 733^{* *}$ &,- 049 &,- 152 &,$- 301^{*}$ \\
\hline 9 & & & & & & & & & 1,00 & 0,044 & $-0,038$ &,- 141 & 0,097 &, $390^{* *}$ & 0,102 \\
\hline 10 & & & & & & & & & & 1,00 & $-0,127$ & 0,128 & ,309* &, $277^{*}$ & 0,125 \\
\hline 11 & & & & & & & & & & & 1,00 &,$- 784^{* *}$ &,- 155 &,$- 394^{* *}$ &,$- 370^{* *}$ \\
\hline 12 & & & & & & & & & & & & 1,00 & 0,251 & ,281* &, $417^{* *}$ \\
\hline 13 & & & & & & & & & & & & & 1,00 &, $667^{* *}$ &, $529^{* *}$ \\
\hline 14 & & & & & & & & & & & & & & 1,00 &, $786^{* *}$ \\
\hline 15 & & & & & & & & & & & & & & & 1,00 \\
\hline
\end{tabular}

Nota. 1: MCM - Motivo Conflito com a mãe; 2: MCP - Motivo Conflito com o pai; 3:ICM - Intensidade Conflito com a mãe; 4: ICP - Intensidade Conflito com o pai; 5:CCM - Cooperação Coparental da mãe; 6: CM - Conflito Coparental da mãe; 7: TCM - Triangulação Coparental da mãe; 8: CCP - Cooperação Coparental Paterno; 9: CP - Conflito Coparental do pai; 10: TCP - Triangulação Coparental do pai; 11: CCF - Cooperação Coparental Família; 12: CF - Conflito Coparental Familiar; 13: TCF _ Triangulação Coparental Familiar; 14: AL - Antissociais Leves; 15:AS - Antissociais Severos;**. A correlação é significativa no nível 0,01 (2 extremidades); *. A correlação é significativa no nível 0,05 (2 extremidades). 
Para subsidiar a análise de regressão linear simples, considerou-se que, para a existência significativa de associação entre os elementos $p<0,05$. A partir desses parâmetros, estruturou-se análise de regressão linear como forma de avaliar o efeito preditor das dimensões da coparentalidade, do conflito pais-filhos e as variáveis dependentes - condutas antissociais leves e severas. Destaca-se as variáveis preditoras das condutas antissociais leves, quais sejam: triangulação coparental familiar - TCF $(\beta=0,725, p<0,001)$, motivo conflito pai - MCP $(\beta=0,438, p=0,037)$, conflito coparental pai - CP $(\beta=0,429, p=0,017)$, e intensidade conflito pai - ICP $(\beta=0,362, p=0,029)$.

$\mathrm{E}$ os preditores significativos das condutas antissociais severas são: conflito coparental familiar - CPF $(\beta=0,897 p=0,003)$, intensidade conflito pai - ICP $(\beta=0,473, p=0,031)$, conflito coparental pai - CP $(\beta$ $=0,447, p=0,049)$, triangulação coparental familiar TCF $(\beta=0,409, p=0,033)$.

Nos dois modelos de regressão, o $\mathrm{R}^{2}$ - coeficiente de determinação ou explicativo da regressão, pode ser compreendido pelo conjunto de variáveis independentes (CF, MCP, CP, ICP - para AL e CPF, ICP, CP, TCF - para AS) e a variável critério ou dependente - condutas antissociais (Dancey \& Reidy, 2013). No caso dos comportamentos leves, é explicado em $76,70 \%\left(\mathrm{R}^{2}\right.$ $0,767)$ enquanto que nos comportamentos severos é explicado em $85,40 \%\left(\mathrm{R}^{2} 0,854\right)$.

\section{Discussão}

Entre os resultados obtidos nesta pesquisa, destaca-se a comparação estabelecida entre gênero e o envolvimento em atos infracionais - sintomas externalizantes. Apurou-se que, dentre os adolescentes, $53,2 \%$ eram meninas, dado que vai de encontro à maioria dos estudos que associam o não cumprimento de regras/normas, as condutas agressivas e violência aos meninos, enquanto que as meninas estariam mais propícias a apresentar sintomas internalizantes, como depressão e ansiedade (Feinberg et al., 2007; Riina \& McHale, 2014; Teubert \& Pinquart, 2010). Além disso, o grupo apresentou idade média entre 14,48 anos (DP $=1,46)$ período em que os adolescentes experienciam várias mudanças e a necessidade de questionar a autoridade e limites, e essas situações, somadas a um convívio familiar em que, por vezes, a qualidade do relacionamento coparental é fragilizada pela constância e intensidade dos conflitos interparentais, acarreta implicações no desenvolvimento do adolescente, propiciando a externalização, com maior intensidade, de comportamentos de risco (Kouros, Cummings, \& Davies, 2010; Mosmann et al., 2017).

Quanto ao gênero dos adolescentes envolvidos em atos infracionais, de forma geral, há uma prevalência de meninos envolvidos em condutas antissociais e submetidas às medidas socioeducativas

Tabela 2.

Comportamentos Antissociais Leves (AL)

\begin{tabular}{lllll}
\hline Preditores & $\boldsymbol{B}$ & $\boldsymbol{E P}$ & B & $\boldsymbol{P}$ \\
\hline Triangulação Coparental Familiar (TCF) & 2,409 &, 507 &, 725 &, 000 \\
Motivo Conflito Pai (MCP) &, 603 &, 266 &, 438 &, 037 \\
Conflito Coparental Pai (CP) &, 805 &, 305 &, 429 &, 017 \\
Intensidade Conflito Pai (ICP) & $-1,548$ &, 651 &, 362 &, 029 \\
\hline
\end{tabular}

Tabela 3.

Comportamentos Antissociais Severos (AS)

\begin{tabular}{lllll}
\hline Preditores & $\boldsymbol{B}$ & $\boldsymbol{E P}$ & B & $\boldsymbol{P}$ \\
\hline Conflito Coparental Familiar (CPF) &, 573 &, 176 &, 897 &, 003 \\
Intensidade Conflito Pai (ICP) &,- 618 &, 260 &, 473 &, 031 \\
Conflito Coparental Pai (CP) &, 261 &, 122 &, 447 &, 049 \\
Triangulação Coparental Familiar (TCF) &, 416 &, 178 &, 409 &, 033 \\
\hline
\end{tabular}

Psico-USF, Bragança Paulista, v. 25, n. 2, p. 343-355, abr./jun. 2020 
(SINASE/2016), desencadeando significativo número de pesquisas sobre os infratores (Costa \& Santos, 2016; Nardi \& Dell'Aglio, 2012; Nardi, Jahn, \& Dell'Aglio, 2014). Contudo, conforme Aranzedo (2015, p. 266) "essa realidade pode favorecer a inobservância das singularidades presentes nas histórias do envolvimento das meninas nos atos infracionais", assim não podemos descurar que a participação de meninas vem apresentando índices crescentes e peculiaridades que merecem reflexões (Aranzedo, 2015; Mello, 2015).

As adolescentes da pesquisa envolveram-se em atos infracionais considerados de menor potencial ofensivo, até por que o lócus das condutas foi o espaço escolar. Observa-se que a atitude agressiva que gerou lesões, vias de fato ou ainda as agressões verbais - injúrias e calúnias constituem-se em situações conflitivas que permeiam a realidade de muitas escolas envolvidas (Silva, Oliveira, Bandeira, \& Souza, 2012), comprometendo não só desempenho escolar, mas, em especial, o desenvolvimento biopsicosocial das jovens. É possível refletir pelos resultados apurados que essas meninas que se envolveram nesses fatos, frente aos fatores contributivos como relação e estilo coparental, reproduziram comportamentos ofensivos, abusivos e/ou violentos como uma resposta a resolução dos conflitos, replicando entre os pares as práticas parentais (castigos/rigor excessivos etc.) inadequadas que vivenciaram em suas famílias.

A partir da análise de regressão, identificaram-se as variáveis que foram preditoras das condutas antissociais leves e severas, e os dados apontaram que a composição das dimensões da coparentalidade e do conflito pai-filhos se demonstraram fortemente explicativas para o envolvimento em atos infracionais, em especial, as dimensões que envolvem o pai - motivo, intensidade e conflito, além da triangulação. Esses preditores evidenciam que as dificuldades estabelecidas na relação entre os cuidadores reverberam na saúde da prole, bem como indicam que os filhos não ficam imunes aos conflitos e as discussões com o pai e, ainda, quando envolvidos em coligações intergeracionais nas quais o adolescente é impelido a aliar-se a um dos cuidadores em detrimento do outro (Pedro \& Ribeiro, 2015). Essas dinâmicas podem desencadear nos adolescentes condutas que acirram mais o ambiente familiar já conflituoso, gerando um convívio ainda mais estressante para os cuidadores, implicando em comportamentos parentais negativos como punições excessivas e inadequadas, desencadeando, por sua vez, mais conflitos coparentais (Feinberg et al., 2007), o que configura como um ciclo vicioso.
Nos dados aferidos, apurou-se, no caso das condutas antissociais leves, duas dimensões da coparentalidade (Triangulação Coparental Familiar - TCF e Conflito Coparental Pai - CP) e duas do conflito pais-filhos (Motivo Conflito Pai - MCP e Intensidade Conflito Pai - ICP). Foram significativas para explicar o modelo, das quais merece destaque a dimensão da triangulação coparental familiar (TCF) cujo valor é de 0,725 , substancialmente maior dos que as outras variáveis.

Por sua vez, nos comportamentos antissociais severos identificaram-se três dimensões da coparentalidade (Conflito Coparental Familiar - CPF, seguido por Conflito Coparental Pai - CP e Triangulação Coparental Familiar - TCF) e somente uma variável do conflito pais-filhos (Intensidade Conflito Pai - ICP), que restaram significativas para explicar o modelo. Contudo, nas condutas severas, o conflito coparental familiar - CPF apresenta o valor de 0,897, bastante superior às demais dimensões.

Observa-se que a dimensão da coparentalidade - triangulação coparental familiar, mesmo com poder explicativo distinto, é preditor em ambas as condutas, situação que se repete com o conflito coparental do pai e o preditor intensidade conflito com o pai. Há distinções entre os comportamentos antissociais leves e severos quanto aos motivos conflito com o pai para as condutas leves e a dimensão de coparentalidade conflito familiar nos severos.

Nas condutas leves, a triangulação familiar assume papel preditor relevante - maior poder explicativo, na qual se identifica a conflitiva instalada entre os cuidadores e o envolvimento do filho no embate entre os cuidadores, seguido dos motivos de conflito com o pai, na sequência, o conflito coparental do pai e a intensidade do conflito com o pai. Verifica-se que, nas condutas leves, a figura materna se faz presente só na variável triangulação coparental familiar, ensejando um clima familiar tenso ou conflituoso, mas marcadamente mais associado à figura paterna, o que reverbera nas outras variáveis e via de consequência nos comportamentos - conduta do adolescente.

Já nos comportamentos antissociais severos, o conflito coparental familiar apresenta maior poder preditor, isto é, há o reconhecimento do conflito entre os cuidadores quanto à forma de cuidar e educar a prole. A segunda dimensão de destaque é o conflito coparental do pai, seguido pelo preditor intensidade do conflito com pai e, por fim, triangulação coparental familiar. Nas condutas severas, foram identificadas três dimensões da coparentalidade e uma variável do 
conflito pais-filhos, fato que evidencia que a forma como é entabulada a relação entre os cuidadores, a forma e frequência dos conflitos, desacordos e discussões, somados às "alianças" e coalisões intergeracionais nas quais o adolescente é envolvido ostensivamente, reverberam de forma singular no funcionamento familiar e dos filhos adolescentes (Pedro \& Ribeiro, 2015).

Reflete-se sobre o papel da triangulação coparental familiar, assumindo distintas expressões nos casos de comportamentos antissociais leves e severos. A literatura aponta dois tipos de triangulação: a primeira divide a coparentalidade, forçando a criança a estabelecer uma coalizão com um dos genitores "contra" o outro, sendo obrigado a "tomar um partido" nessa relação conjugal conflituosa. $\mathrm{Na}$ segunda, devido às dificuldades conjugais dos pais, a criança desenvolve algum sintoma, "obrigando" os cuidadores a desviarem a atenção de seus conflitos e focando nela (Pedro \& Ribeiro, 2015). O primeiro tipo, por ter caráter mais explícito, está mais associado a sintomas de externalização. $\mathrm{O}$ segundo tipo, por se tratar de conflitos conjugais muitas vezes encobertos, associa-se mais a sintomas internalizantes (Machado \& Mosmann, no prelo).

Dessa forma, identifica-se que, nessa amostra, mesmo se tratando somente de sintomas externalizantes, nos casos de comportamentos antissociais leves, a triangulação familiar é a variável com maior poder preditivo, mas mais associada às variáveis do pai, reverberando em menor intensidade de comportamentos de externalização, talvez pela participação não tão ostensiva da mãe. Já nas situações de comportamentos antissociais severos, denota-se mais variáveis da coparentalidade como preditoras, provavelmente indicando envolvimento ostensivo de ambos cuidadores em discórdias associadas aos cuidados com a prole, coalizões e conflitos conjugais, que se expressam em sintomas externalizantes mais graves.

Enquanto que o conflito coparental familiar representa a forma como as figuras parentais se relacionam, as discussões e a discórdia sobre a educação dos filhos, bem como as estratégias para boicotar ou enfraquecer a parentalidade de um dos cuidadores. Essas condutas podem estar associadas a formas ríspidas, rígidas e até violentas de cuidado - supervisão e trato com os filhos adolescentes, o que acaba por potencializar comportamentos externalizantes (Mosmann et al., 2017; Pedro \& Ribeiro, 2015). Assim, adolescentes e crianças que convivem ou testemunham conflitos coparentais podem associar as mais variadas formas de agressões como meio de entabular e resolver suas relações interpessoais. Os resultados encontrados estão em consonância com os estudos de Teubert \& Pinquart (2010) nos quais apresentam resultados de associação entre a coparentalidade com o comportamento dos adolescentes, mais especificamente, no conflito coparental em que se relaciona a sintomas depressivos para os adolescentes indistintamente e comportamentos de risco para meninos. Dados que seguem a mesma linha do estudo apresentado por Baril et al., (2007).

Já a variável explicativa - motivo conflito pai (ICP) visa retratar o relacionamento do adolescente com a figura paterna tanto no que tange aos motivos quanto a sua intensidade. Verificou-se que temas como escola, amizades e namoro, envolver-se em tarefas domésticas ou sair à noite, como também internet, drogas e dinheiro são motivos recorrentes para o desentendimento entre filho(s) e pai.

Cumpre destacar que todas as dimensões avaliadas são importantes para a compreensão do ajustamento psicológico dos adolescentes, bem como é possível conceber que adolescentes não só reconheçam e façam uso dessas dimensões em suas relações familiares e sociais, como uma resposta ao comportamento parental, quer seja frente aos conflitos, a sabotagem, as coalizões, como também a situações mais sutis, como a ausência de apoio, cooperação entre os cuidadores em relação à prole (Teubert \& Pinquart, 2010).

Outra constatação importante no estudo foi a relação estabelecida com a mãe, pois, nos modelos - Tabela 2 e Tabela 3, o conflito envolve sempre a figura paterna. Aduz-se, como a literatura arrola que a mãe pode materializar a importância ou o significado da família, enquanto que o pai pode simbolizar a distância/ausência ou a forma repressiva e de punições exageradas, evidenciando práticas parentais negativas e destrutivas (Zappe \& Dias, 2012). Ou ainda, a mãe pode assumir um papel permissivo, quando nega ou omite o envolvimento do adolescente buscando em vão minimizar os impactos da conduta, perdendo a autoridade sobre os filhos (Predebon \& Giongo, 2015; Rocha \& Sousa, 2013; Sabbag \& Bolsoni-Silva, 2015).

Observa-se, assim, que a vida e as formas que se estabelecem os relacionamentos no ambiente familiar têm implicações diretas na saúde mental da criança e adolescentes. E, conforme as características e dinâmicas estabelecidas em família, podem se tornar tanto um fator de proteção quanto de risco para o adolescente envolver-se com condutas antissociais. 


\section{Considerações Finais}

Com o intento de investigar o papel preditor das dimensões da coparentalidade dos cuidadores, do conflito entre pais-filhos nas condutas antissociais dos adolescentes em conflito com a lei no contexto das práticas restaurativas, este estudo identificou as principais dimensões que impactaram nos adolescentes envolvidos. A análise de um grupo diferenciado - adolescentes no contexto das práticas restaurativas representou um desafio, não só pelo fato de abordar aspectos multidisciplinares, mas por envolver um número substancial de pessoas e órgãos, isto é, Ministério Público, Poder Judiciário, Facilitadores, adolescentes e as suas famílias. O debate da coparentalidade associado aos adolescentes que cometeram atos infracionais buscou discutir dimensões como conflito, triangulação, conflito pais-filhos, ainda pouco exploradas, mas que estão diretamente relacionados com a postura que o adolescente assume frente a sua unidade familiar e sua interação social.

Nesse sentido, a família e os padrões de relacionamento estabelecidos entre os cuidadores, como forma de divisão de práticas educativas, na cooperação e associação estabelecida entre os pais e filhos podem explicar condutas ou problemas que a prole externaliza na adolescência. É fato que, na fase do adolescer, os filhos buscam maior autonomia e independência, o que pode gerar exposição aos riscos e impõe aos cuidadores a necessidade de estabelecer novas estratégias parentais e rever suas relações coparentais, em especial, no que tange à cooperação, o compartilhamento de decisões e a forma como se estabelece a biredicionalidade das relações, tendo em vista que, os sujeitos da unidade familiar são mutuamente influentes. É evidente, portanto, o papel da unidade familiar e todas as dimensões que a envolvem e suas implicações na formação do adolescente.

Apesar das contribuições que este estudo lançou sobre a temática, é importante termos presente que, ao longo da pesquisa, surgiram entraves, pois foram aplicados 124 instrumentos dos quais somente 62 foram considerados válidos para o estudo e, mesmo que a amostra garanta poder estatístico confiável para os objetivos da pesquisa, o fato de terem ocorrido tantos missing impõe a análise sobre a limitação quanto ao volume das questões que o instrumento apresentava e do grau de escolaridade dos entrevistados envolvidos. Para novos trabalhos, torna-se necessário diversificar os instrumentos, adotando, para a ampliação da temática, entrevistas e roteiros semiestruturados, sob um viés qualitativo, a fim de se atingir uma ampla contextualização das relações familiares.

Ademais, os resultados deste estudo podem subsidiar novos trabalhos bem como instrumentalizar políticas públicas que envolvam, não só o adolescente em conflito com a lei, mas a sua unidade familiar, em especial, o pai, para que assim se reflita sobre o seu papel e as formas como este vem entabulando sua relação na unidade familiar, buscando romper com a conflitiva instaurada. Torna-se assim, imprescindível, a ampliação das investigações que instrumentalizem as unidades familiares, escolas etc. para que se tornem um recurso positivo no processo formativo do adolescente em conflito com a lei. É por meio desses estudos que se viabilizará expedientes para a elaboração e aprimoramento de programas como da justiça restaurativa, que orientem preventivamente o adolescente e seu entorno, a fim de mitigar a problemática que envolve o ato infracional na adolescência.

\section{Referências}

Aranzedo, A. C. (2015). "Meninas": Os conflitos com a lei e as representações das medidas socioeducativas. Psicologia e Saber Social, 4(2), 265-276. doi:10.12957/ psi.saber.soc.2015.16413

Baril, M. E., Crouter, A. C., \& McHale, S. M. (2007). Processes linking adolescent well-being, marital love, and coparenting. Journal of Family Psychology, 21(4), 645-654. doi:10.1037/0893-3200.21.4.645

Brasil (2018). Levantamento Anual Sinase 2016. Ministério dos Direitos Humanos (MDH). Recuperado de www.mdh.gov.br/assuntos/criancas-e-adolescentes/...de.../Levantamento_2016.pdf

Borba, P. L. O., Lopes, R. E., \& Malfitano, A. P. S. (2015) Trajetórias escolares de adolescentes em conflito com a lei: Subsídios para repensar políticas educacionais. Ensaio: avaliação e políticas públicas em educação, 23(89), 937-963.

Buehler, C., \& Gerard, J.M. (2002). Marital conflict, ineffective, parenting, and children's and adolescents' maladjustment. Journal of Marriage and Family, 64(1), 78-93. doi:10.1111/j.1741-3737.2002.00078.x

Castro, A. M. F. M., \& Teodoro, M. L. M. (2014). Relações familiares de adolescentes cumprindo medida socioeducativa restritiva de liberdade: Uma revisão narrativa da literatura. Temas em Psicologia, (22), 1-12. 
Costa, L. P., \& Santos, Samara S. (2016). Adolescente em conflito com a lei: Revisando as contribuições de variáveis sociais, familiares e individuais. Estudos e pesquisas em psicologia (Impr.); 16(3): 757-771.

Dancey, C. P., \& Reidy, J. (2013). Estatística sem matemática para psicologia. 5. ed. Porto Alegre: Penso.

Feinberg, M. E. (2003). The Internal structure and ecological context of coparenting: A framework for research and intervention. Parenting: Science and Practice, 3(2), 95-131. doi:10.1111/j.1741-3737.2007.00400.x

Feinberg, M .E., Kan, M. L., \& Hetherington, E. M. (2007). The longitudinal influence of coparenting conflict on parental negativity and adolescent maladjustment. Journal of Marriage and Family, 69(3), 687-702. doi:10.1111/j.1741- 3737.2007.00400.x

Formiga, N. S. (2014). Dinâmica interna familiar e condutas desviantes: Verificação de um modelo teórico em jovens brasileiros. Revista de Psicologia da Criança e do Adolescente, 5(2), 115-128.

Grangeiro, A. S. M. (2014). Escala de comportamentos antissociais: Construção e evidências de validade (Master'sthesis). Universidade Federal do Ceará, Fortaleza, Ceará, Brasil. Recuperado de www.repositorio.ufc.br./ bitstream/ricefc/7744/1/2014DISASMGRANGEIRO.pdf

Hair, J. F., Black, W. C., Babin, B. J., Anderson, R. E., \& Tatham, R. L. (2009). Análise multivariada de dados. Bookman Editora.

Kouros, C. D., Cummings, E. M., \& Davies, P. T. (2010). Early trajectories of interparental conflict and externalizing problems as predictors of social competence in preadolescence. Development and psychopathology, 22(3), 527-537. doi:10.1017/ S0954579410000258

Lamela, D., \& Figueiredo, B. (2016). Coparenting after marital dissolution and children's mental health: A systematic review. Jornal de Pediatria. 92(4), 331-342. doi: 10.1016/j.jped.2015.09.011

Lamela, D., Nunes-Costa, R., \& Figueiredo, B. (2010). Modelos teóricos das relações coparentais: Revisão crítica. Psicologia em Estudo, 15(1), 205-216. doi:10.1590/S0102-79722013000100003

Machado, M. R., \& Mosmann, C. P. Conflito e triangulação coparental, regulação emocional e problemas externalizantes em adolescentes. (no prelo). Paidéia.
Margolin, G., Gordis, E. B., \& John, R. S. (2001). Coparenting: A link between marital conflict and parenting in two parent families. Journal of family Psychology, 15(1), 3-21. doi:10.1037/0893-3200.15.1.3

Mello, M. M. P. Bastos (coord.) (2015). Dos espaços aos direitos: A realidade da ressocialização na aplicação das medidas socioeducativo de internação das adolescentes do sexo feminino em conflito com a lei nas cinco regiões. Pesquisadores: Bastos, C.A.V. [et al.]. Brasília: Conselho Nacional de Justiça. Recuperado de www.cnj. jus.br

Mosmann, C. P., Machado, M. R., Costa, C. B., Gross, P. R. C., \& Abs, D. (2018). Propriedades psicométricas da versão brasileira do The Coparenting Inventory for Parents and Adolescents (CI-PA). Avaliação Psicológica, 17(3), 399-406. doi:10.15689/ ap.2018.1703.14281.13

Mosmann, C. P., Costa, C. B., Einsfeld, P., Silva, A. G. M. \& Koch, C. (2017). Conjugalidade, parentalidade e coparentalidade: Associações com sintomas externalizantes e internalizantes em crianças e adolescentes. Estudos de Psicologia, 34(4), 487-498.

Mosmann, C., Costa, C. B., Silva, A. G. M. D., \& Luz, S. K. (2018). Filhos com sintomas psicológicos clínicos: Papel discriminante da conjugalidade, coparentalidade e parentalidade. Temas em Psicologia, 26(1), 429-442. doi:10.9788/TP2018.1-17Pt

Nardi, F. L., \& Dell'Aglio, D. D. (2012). Adolescentes em conflito com a lei: Percepções sobre a família. Psicologia: Teoria e Pesquisa, 28(2), 181-191.

Nardi, F. L., Jahn, G. M., \& Dell'Aglio, D. D. (2014). Perfil de adolescentes em privação de liberdade: Eventos estressores, uso de drogas e expectativas de futuro. Psicologia em Revista, 20(1), 116-137. doi:10.5752/P.1678-9523.2014v20n1p116

Neumann, A. P., \& Zordan, E. P. (2013). As reverberações da separação conjugal dos pais no relacionamento entre irmãos. Pensando famílias, 17(2), 35-47.

Nunes, M. C. A., Andrade A. G. S., \& Morais, N. A. (2013). Adolescentes em conflito com a lei e família: Um estudo de revisão sistemática da literatura. Contextos Clínicos. 6(2), 144-156.

Padovani, R. D. C., Schelini, P. W., \& Williams, L. C. D. A. (2009). Inventário de Resolução de Problemas Sociais - Revisado: Evidências de validade e 
precisão. Avaliação Psicológica: Interamerican Journal of Psychological Assessment, 8(2), 267-276.

Pedro, M. F., \& Ribeiro, M. T. (2015). Adaptação Portuguesa do Questionário de Coparentalidade: Análise fatorial confirmatória e estudos de validade e fiabilidade. Psicologia Reflexão e Crítica, 28(1), 116-125.

Pereira, C. C. M., Zambalde, C. G. S., Lambert, C. C., Costa, P. M., Machado, J. S. A. \& Botti, N. C. L. (2016). Características pessoais e familiares entre adolescentes infratores. Revista de enfermagem do centro-oeste mineiro, 6(2), 2212-2222. doi:10.19175/ recom.v6i2.991

Predebon, J., \& Giongo, C. (2015). A família com filhos adolescentes em conflito com a lei: Contribuições de pesquisas brasileiras. Pensando Famílias, 19(1), 88-104.

Riina, E. M., \& McHale, S. M. (2014). Bidirectional influences between dimensions of coparenting and adolescent adjustment. Journal of youth and adolescence, 43(2), 257-269.

Rocha, T. T., \& Sousa, G. S. (2013). Olhar materno diante do ato infracional cometido pelo filho adolescente. Revista Fragmentos de Cultura-Revista Interdisciplinar de Ciências Humanas, 23(4), 425-438. doi: 10.18224/ frag.v23i4.2968

Rossato, L., \& Souza, T. M. C. (2014). Psicologia e adolescentes em conflito com a lei: Reflexões a partir do estágio. Revista SPAGESP, 13(1), 112-122.

Sabbag, G. M., \& Bolsoni-Silva, A.T. (2015). Interações entre mães e adolescentes e os problemas de comportamento Arquivos Brasileiros de Psicologia, 67(1): 68-83.

Salmaso, M. N. (2016). Uma mudança de paradigma e o ideal voltado à construção de uma cultura de paz.
Cruz, F.B. (Coord.). Justiça Restaurativa. Brasília: CNJ, 18-64.

Sbicigo, J. B., \& Dell'Aglio, D. D. (2012). Family environment and psychological adaption in adolescents. Psicologia: Reflexão e Crítica, 25(3), 615-622.

Silva, C. E., Oliveira, R. V., Bandeira, D. R., \& Souza, D. O. (2012). Violência entre pares: Um estudo de caso numa escola pública de Esteio/RS. Psicologia Escolar e Educacional, 16(1).

Silveira, M. A. D. S. D., Maruschi, M. C., \& Bazon, M. R. (2012). Risco e proteção para o engajamento de adolescentes em práticas de atos infracionais. Journal of Human Growth and Development, 22(3), 348-357.

Teubert, D., \& Pinquart, M. (2010a). The Coparenting Inventory for Parents and Adolescents (CI -PA). European Journal of Psychological Assessment, 27(3), 206-215.

Teubert, D., \& Pinquart, M. (2010b). The association between coparenting and child adjustment: A meta-analysis. Parenting, 10(4), 286-307. doi:10.1080/ 15295192.2010.492040

Trindade, M. T., \& Mosmann, C. P. (2015). Discriminant profile of young internet dependents: The role of family relationships. Paidéia (Ribeirão Preto), 25(62), 353-361. doi:10.1590/1982-43272562201509.

Vasconcellos, M. J. E. de. (2002). Pensamento Sistêmico. O novo paradigma da ciência. Rio de Janeiro: Papirus.

Zappe, J. G., \& Dias, A. C. (2012) Violência e fragilidades nas relações familiares: Refletindo sobre a situação de adolescentes em conflito com a lei Estudos de Psicologia, 17(3), 389-395.

Recebido em: 02/10/2018 Reformulado em: 13/05/2019 
Sobre os autores:

Cristiane Koch é doutora em Psicologia (Unisinos), mestre em Ciências Criminais (PUCRS), graduada em Ciências Jurídica e Sociais e em Filosofia (Unisinos) e professora de Direito da UCS e advogada.

ORCID: orcid.org/0000-0001-8610-2144

E-mail:ckoch@ucs.br

Jeferson Rodrigo Schaefer é graduando em Psicologia, Universidade do Vale do Rio dos Sinos - UNISINOS e bolsista PROBIC/FAPERGS - Núcleo de Estudos em Casais e Famílias - NECAF/UNISINOS.

ORCID: https://orcid.org/0000-0002-7613-2902

E-mail: jeferson9282@gmail.com

Mariana Cunha Schneider é graduanda em Psicologia pela Universidade do Vale do Rio dos Sinos - UNISINOS e bolsista PIBIC/CNPQ - Núcleo de Estudos em Casais e Famílias - NECAF/UNISINOS.

ORCID: https://orcid.org/0000-0002-7577-1710

E-mail: mailto:marianacunhaschneider@gmail.com

Clarisse Pereira Mosmann é psicóloga (PUCRS), especialista em Terapia de Casal e Família (STIRPE/Madrid), doutora em Psicologia (PUCRS), professora do curso e do Programa de Pós-Graduação em Psicologia da Universidade do Vale do Rio dos Sinos (UNISINOS) e coordenadora do Núcleo de Estudos em Casais e Famílias - NECAF/ UNISINOS.

ORCID: orcid.org/0000-0002-9275-1105

E-mail: clarissepm@unisinos.br

Contato com os autores:

Universidade de Caxias do Sul - UCS. - Bloco 58. Rua Francisco Getúlio Vargas, 1130

Petrópolis, Caxias do Sul-RS, Brasil

CEP: 95070-560

Telefone: (54) 32182520 
